\section{Endoscopic biopsy: a simple guide for beginners}

In routine endoscopic practice, usage of biopsy forceps is inevitable. But most of the times we have to work under time constraints, particularly in high volume centers and we are in a hurry to complete the procedure, especially when we need to take multiple biopsies. Taking a biopsy in a hurry may lead to mucosal trauma, bleeding and possible perforation. ${ }^{1,2}$ It is sometimes difficult to observewhen to slow down the insertion of biopsy forceps through the working channel of the endoscope to decrease chances of trauma, particularly for beginners.

We have observed that the endoscopist has to push the biopsy forceps 16 to 20 times before it reaches the gastrointestinal lumen in the standard gastroscope. When the endoscopy assistant starts extending his elbow and when his arm crosses the level of trunk towards endoscopist, only 2 to 4 further pushes are needed for the biopsy forceps to reach the lumen (Figures $1 \& 2$ ). So by just observing assistant's movements which usually lie within the visual field of the endoscopist, we can slow the rate of pushing the biopsy forceps once the assistant's arm crosses the level of the trunk. Following this method reduces the chances of trauma and results in the smooth introduction of the biopsy forceps into the gastrointestinal lumen. This holds good for standard gastroduodenoscopes, colonoscopes and enteroscopes as well, when standard biopsy forceps recommended by endoscope manufacturers are used. We feel our observation or any other similar relevant observations by endoscopists can be helpful in avoiding trauma to the mucosa and damage to biopsy forceps, especially for the beginners.

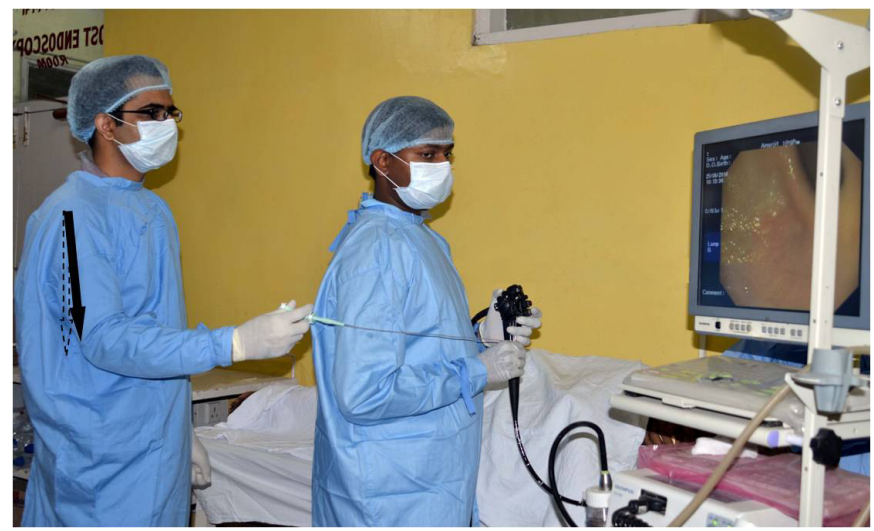

Figure: 1 The assistant's elbow in flexion position and arm (black arrow) at the level of trunk (arrow with dotted outline) whilst initially introducing the biopsy forceps.

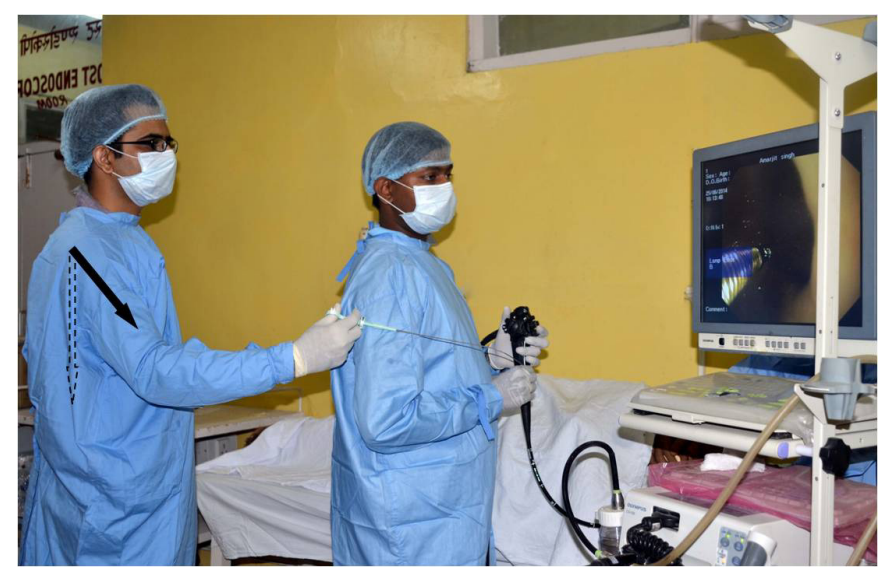

Figure: 2 After flexion shoulder along with extension at the elbow (black arrow) and once arm crosses the level of trunk (arrow with dotted outline) of the assistant, biopsy forceps (red arrow) reaches the lumen and comes into view.

REDDY Y RAMI, AC ARUN, SK SINHA,

R KOCHHAR

Correspondence: Dr.Yalaka Rami Reddy Department of Gastroenterology, Post Graduate Institute of Medical Education and Research (PGIMER), Chandigarh, 160012, India Email:yrrpgi@gmail.com

\section{References}

1. Dominitz JA, Eisen GM, Baron TH, Goldstein JL, Hirota WK, Jacobson BC, et al. Complications of colonoscopy. Gastrointest Endosc. 2003;57:441-5.

2. Eisen GM, Baron TH, Dominitz JA, Faigel DO, Goldstein JL, Johanson JF, et al. Complications of upper GI endoscopy. Gastrointest Endosc. 2002;55:784-93.

\section{Successful living donor liver transplantation with partial nephrectomy for co-existing renal cell carcinoma and cirrhosis}

\section{Introduction}

Patients with cirrhosis are at a high risk of liver failure and mortality following non-transplant surgery. ${ }^{1,2}$ The presence of 